\title{
ASAP1 gene polymorphisms are associated with susceptibility to tuberculosis in a Chinese Xinjiang Muslim population
}

\author{
XIANHUA WANG ${ }^{1}$, AIGUO MA ${ }^{1}$, XIUXIA HAN ${ }^{1}$, AISHAN LITIFU ${ }^{2}$ and FENG XUE ${ }^{3}$ \\ ${ }^{1}$ The School of Public Health, Qingdao University Medical College, Qingdao, Shandong 266021; \\ ${ }^{2}$ Department of Respiratory Medicine, Xinjiang Uygur Autonomous Region Chest Hospital, Urumqi, Xinjiang 830049; \\ ${ }^{3}$ Department of Tuberculosis, Xinjiang Uygur Autonomous Region Center for Disease Control and \\ Prevention, Xinjiang Uygur Autonomous Region, Urumqi, Xinjiang 830001, P.R. China
}

Received August 22, 2017; Accepted January 10, 2018

DOI: $10.3892 /$ etm.2018.5800

\begin{abstract}
Seven single-nucleotide polymorphism (SNP) sites located in ASAP1 gene have been found associated with tuberculosis (TB) susceptibility by genome-wide association studies in Russia. The case-control study was carried out to test whether these seven SNPs were associated with susceptibility to TB in a Chinese Xinjiang Muslim population. The seven SNPs were genotyped in a case-control design that included 780 Xinjiang Muslim subjects (400 TB patients and 380 controls). Multiplex PCR and direct sequencing were used to detect ASAP1 gene polymorphisms. Hardy-Weinberg equilibrium test was performed to test whether the sample was from genetic equilibrium population. The associations of SNPs with TB risk were determined by the distributions of allelic frequencies and different genetic models. Significant differences of the allelic distribution of rs4733781 and rs1017281 in ASAP1 gene were observed between control group and TB group. A allele of rs4733781 was associated with TB risk (TB vs. control, $\mathrm{OR}=1.242$; 95\% CI: $1.004-1.537, \mathrm{P}=0.046$ ); While in rs1017281 site, $\mathrm{G}$ allele was associated with increased risk for TB (TB vs. control, OR: 0.792, 95\% CI: 0.643-0.976, $\mathrm{P}=0.028)$. The recessive model of rs4733781 (CC vs. AC+AA) in Xinjiang Muslim populations was associated with a lower TB risk $[\mathrm{P}=0.003, \mathrm{OR}=0.51(0.324-0.802)]$, while the recessive model of rs1017281 (GG vs. AG+AA) was associated with a higher $\mathrm{TB}$ risk $[\mathrm{P}=0.011, \mathrm{OR}=1.792(1.135-2.828)]$. Using case-control analysis, we identified that two genetic polymorphism sites in the ASAP1 relate to host susceptibility of TB in a Chinese Xinjiang Muslim population.
\end{abstract}

Correspondence to: Dr Aiguo Ma or Dr Xiuxia Han, The School of Public Health, Qingdao University Medical College, 38 Dengzhou Road, Qingdao, Shandong 266021, P.R. China

E-mail: aiguomamed@163.com

E-mail: xiuxiahanmed@163.com

Key words: ASAP1, tuberculosis, single-nucleotide polymorphism, Xinjiang Muslim population

\section{Introduction}

Tuberculosis (TB) is one of the public health emergencies all over the world and severely affects human health. TB is especially epidemic in China, which accounted for $12 \%$ of the global total cases in 2012 (1). According to 2010 National Technical Steering Group of the Epidemiological Sampling Survey for TB, the weighted prevalence of active, smear-positive, bacteriological positive pulmonary TB were 459/100,000, $66 / 100,000,119 / 100,000$, respectively (2). The geographical distribution of TB prevalence presented that it was relatively low in the eastern parts and high in the western parts, and the prevalence rates of active pulmonary TB, Mycobacteriumpositive pulmonary TB and smear-positive pulmonary TB in Xinjiang Uygur autonomous region were all higher than that in other provinces $(3,4)$, which demonstrated that Xinjiang bore a heavy burden of TB.

TB is caused by Mycobacterium tuberculosis (MTB), which has infected around a third of the world population (5), but only $10 \%$ of those infected progress to active disease in their lifetime, and up to $90 \%$ of infected people are asymptomatic with a latent infection (6). Susceptibility to TB varies between different people. Since 1890s, how genetic factors affect clinical outcomes with MTB infection was illustrated by a series of research. For example, several twin studies have found that concordance of TB was higher in monozygotic twins compared to dizygotic twins (7-9). Beyond that, adoption research, Genome-wide association studies, and case-control analysis have been performed to demonstrate that the associations between individual genetics and susceptibility to TB (10-12). These indicated that host genetic factors are important determinants of TB susceptibility.

The ASAP1 gene (known as AMAP1 or DDEF1), located at 8q24.1-8q24.2, encodes an Arf GTPase-activating protein (Arf GAP), which is a multifunctional scaffold protein that induces hydrolysis of GTP bound to the ADP ribosylation factor family GTP-binding (Arf) proteins (13-15). ASAP1 has been implicated in regulating cell motility and invasion $(16,17)$. It was found to functionally link with the progression and metastasis of tumor cells, including ovary cancer (18), prostate cancer (19), and breast cancer $(20,21)$. Curtis et al (14) found that the expression of ASAP1 gene in MTB-infected dendritic 
cells was dramatically reduced, which may impair DC migration, suggesting a potential mechanism that predisposes to TB.

Genome-wide association study is an effective way (9) to screen for the genes exerting the best population-wide impact on susceptibility to a multifactorial disease (22). By using this method, Curtis et al identified a novel ASAP1 gene which was associated with susceptibility to TB (14). Eleven single-nucleotide polymorphisms (SNP)s were identified with significant association with susceptibility to MTB $\left(\mathrm{P}<5 \times 10^{-8}\right)$. Seven out of the most significantly associated ASAP1 SNPs were individually genotyped to replicate their discovery, the most significant association was at $\mathrm{rs} 4733781\left(\mathrm{P}=2.6 \times 10^{-11}\right)$. Then the associations between ASAP1 SNPs and susceptibility to MTB were studied in Chinese population, but not in Xinjiang minorities $(23,24)$. As far as we know, it is the first study which explored association between ASAP1 SNPs and susceptibility to MTB in Xinjiang Muslim populations.

Owing to population heterogeneity, different races have different causative polymorphisms (25). In this study, we selected a set of SNPs within the entire ASAP1 gene and used case-control analysis in Xinjiang Muslim populations to investigate whether ASAP1 SNP was associated with TB risk.

\section{Materials and methods}

Subject. In this study all the participants, including 400 TB patients and 380 control subjects, were of Xinjiang Muslim ethnicity. For TB patients, there were 322 Uyghur patients, 46 Kazak patients and 32 Hui nationality patients. Correspondingly, the Uyghur patients, Kazak patients and Hui nationality patients were 306,44 and 30 , respectively in the control group.

Eligible cases were adult patients who were newly diagnosed with active TB. These patients have evident lesions of TB through simple computed tomography, X-ray, and positive results of sputum smears and cultures for mycobacteria. Patients with HIV-infection, hepatitis virus infection, immunodeficiency disease, and other lung diseases were excluded from this cohort. Healthy controls were nationality-, age- and sexmatched Xinjiang minorities from Department of Respiratory Medicine, Xinjiang Uygur Autonomous Region Chest Hospital, the Xinjiang Uygur Autonomous Region, Urumqi, Xinjiang, China. The controls were negative both for history of TB and T-SPOT assay. All participants were BCG vaccinated.

Each patient and control enrolled in this study provided a written informed consent. The study protocol conformed to the ethical guidelines of the 1975 Declaration of Helsinki and was approved by the Ethics Committee of Department of Respiratory Medicine, Xinjiang Uygur Autonomous Region Chest Hospital.

Blood sample collection, DNA isolation, purification and quality test. Peripheral blood samples $(10 \mathrm{ml})$ was collected from each participants and stored at $-80^{\circ} \mathrm{C}$. Genomic DNA was extracted from peripheral blood collected from $400 \mathrm{~TB}$ patients and 380 non-TB controls using a Genomic DNA Mini Preparation kit (Beyotime, Shanghai, China) according to the manufacturer's instructions. Then a reference gene ASAP1 was used for qualifying the extracted samples by polymerase chain reaction (PCR) and electrophoresis. Obvious imaging
Table I. Clinical characteristics of patients and controls.

\begin{tabular}{lcccc}
\hline Characteristics & TB patients & Control & $\chi^{2}$ & P-value \\
\hline Number & 400 & 380 & & \\
Age (years) & $55.4 \pm 12.4$ & $55.7 \pm 12.1$ & & 0.675 \\
Nationality & & & 0.281 & 0.869 \\
Uyghur & $322(79.8 \%)$ & $306(81.2 \%)$ & & \\
Kazakhs & $46(11.5 \%)$ & $44(11.0 \%)$ & & \\
Hui & $32(8.8 \%)$ & $30(7.9 \%)$ & & \\
Sex & & & 0.666 & 0.415 \\
Male & $237(59.2 \%)$ & $236(62.1 \%)$ & & \\
Female & $163(40.8 \%)$ & $144(37.9 \%)$ & & \\
Family history & & & 1.319 & 0.251 \\
of TB & & & & \\
Yes & $38(9.5 \%)$ & $29(7.2 \%)$ & & \\
No & $362(90.5 \%)$ & $371(92.8 \%)$ & & \\
\hline
\end{tabular}

TB, tuberculosis.

was regarded as qualified, or genomic DNA would be extracted again.

\section{Gene polymorphism detection}

SNP selection. According to Curtis et al (14), 7 polymorphic sites in ASAP1 gene were adopted in our study, including rs1017281, rs10956514, rs1469288, rs17285138, rs2033059, rs4733781, rs12680942. The details of primers are presented in Table I.

Primer design. After searching the whole ASAP1 gene sequence in Genebank, 7 primers pairs were designed and synthetized by Shanghai Biological Engineering Company (Table II).

Multiplex PCR amplification and product purification. SNPs were genotyped by multiplex PCR reaction using AmpliTaq Gold $^{\circledR} 360$ Master Mix (Applied Biosystems, Carlsbad, CA, USA), according to its protocol. The PCR reaction was designed to amplify fragments covering all 7 SNP loci. The PCR product was purified using PCR Clean Up kit (Beyotime) according to the protocol.

SNP detection. Polymorphic loci genotypes were detected using Sanger sequencing.

Statistical analysis. Statistical power was calculated by a post hoc power analysis by G*Power 3.1.9.2 software (Program written, conceptualized and designed by Franz, Universitat Kiel, Germany; freely available windows application software). The data were analyzed by SPSS 18.0 software (SPSS Inc., Chicago, IL). Continuous variables and categorical data were compared by $\chi^{2}$ test. Hardy-Weinberg equilibrium test was used to detect whether the two groups were in genetic equilibrium. Genotype frequency comparisons between groups were presented as odds ratio (OR) and $95 \%$ confidence interval (CI). Haploview 4.2 (26) was used to performed linkage disequilibrium analysis. The tests were 2 -sided and 
Table II. SNPs with their primers.

\begin{tabular}{|c|c|c|c|c|c|}
\hline SNP ID & Gene & SNP & Primer sequence $\left(5^{\prime}-3^{\prime}\right)$ & $\begin{array}{c}\text { Annealing } \\
\text { temperature }\left({ }^{\circ} \mathrm{C}\right)\end{array}$ & $\begin{array}{l}\text { Fragment } \\
\text { size (bp) }\end{array}$ \\
\hline rs10956514 & ASAP1 & $\mathrm{A} / \mathrm{G}$ & $\begin{array}{l}\text { GGCCACTGGCAAAAATAAGC } \\
\text { AGTTGTCCAACTGCGGATAC }\end{array}$ & 55 & 320 \\
\hline rs4733781 & ASAP1 & $\mathrm{A} / \mathrm{C}$ & $\begin{array}{l}\text { CAAATGAACCCCCATAAAGG } \\
\text { CCAGTGGCTGCATCCTACAT }\end{array}$ & 55 & 238 \\
\hline rs1017281 & ASAP1 & $\mathrm{C} / \mathrm{T}$ & $\begin{array}{l}\text { TATCTAATGTGCAGGGGATTG } \\
\text { TCTCCCTTTTGCAGCTCACA }\end{array}$ & 55 & 298 \\
\hline rs1469288 & ASAP1 & $\mathrm{C} / \mathrm{T}$ & $\begin{array}{l}\text { TCCACACTGCTGAAAAATCTG } \\
\text { AAGGATGTGGGGAGTTGAGG }\end{array}$ & 55 & 521 \\
\hline rs2033059 & ASAP1 & $\mathrm{C} / \mathrm{T}$ & $\begin{array}{l}\text { ACATACGTGGTGGTTGACTG } \\
\text { TCCCAAAGCACAGAGGAAGA }\end{array}$ & 54 & 393 \\
\hline rs12680942 & ASAP1 & $\mathrm{A} / \mathrm{G}$ & $\begin{array}{l}\text { GCTGCTATAAAGACCCAGAAG } \\
\text { GGCCATTTCTCCAAAGCCTCT }\end{array}$ & 56 & 207 \\
\hline rs17285138 & ASAP1 & $\mathrm{A} / \mathrm{T}$ & $\begin{array}{l}\text { CTGACTTGGTGCCAGCCTAC } \\
\text { TGCTTTCCCAGAGCTTTCAG }\end{array}$ & 54 & 319 \\
\hline
\end{tabular}

SNP, single-nucleotide polymorphism; ASAP1, Arf GTPase-activating protein-1.

Table III. Genotyping of rs1469288, rs2033059, rs12680942, Rs17285138 in TB and control group in Xinjiang Muslin population.

\begin{tabular}{|c|c|c|c|c|c|}
\hline Site/genotype/allele & SNP & TB patients & Control & OR $(95 \% \mathrm{CI})$ & P-value \\
\hline rs1469288 & HWE(P) & & & & 0.20 \\
\hline \multirow[t]{3}{*}{ Genotype } & AA & $203(50.8 \%)$ & $194(51.1 \%)$ & & \\
\hline & $\mathrm{AG}$ & $169(42.4 \%)$ & $160(42.2 \%)$ & & \\
\hline & GG & $28(6.8 \%)$ & $26(6.7 \%)$ & & 0.994 \\
\hline \multirow[t]{2}{*}{ Allele } & $\mathrm{A}$ & $575(71.9 \%)$ & $548(72.1 \%)$ & & \\
\hline & G & $225(28.1 \%)$ & $212(27.9 \%)$ & $0.989(0.793-1.233)$ & 0.919 \\
\hline rs2033059 & HWE(P) & & & & 0.45 \\
\hline \multirow[t]{3}{*}{ Genotype } & $\mathrm{CC}$ & $130(32.5 \%)$ & $108(28.5 \%)$ & & \\
\hline & CT & $192(48.0 \%)$ & $203(53.3 \%)$ & & \\
\hline & $\mathrm{TT}$ & $78(19.5 \%)$ & $69(18.2 \%)$ & & 0.293 \\
\hline \multirow[t]{2}{*}{ Allele } & $\mathrm{C}$ & $452(56.5 \%)$ & $419(55.1 \%)$ & & \\
\hline & $\mathrm{T}$ & $348(43.5 \%)$ & $341(44.9 \%)$ & $1.507(0.866-1.291)$ & 0.586 \\
\hline rs 12680942 & HWE(P) & & & & 0.99 \\
\hline \multirow{3}{*}{ Genotype } & AA & $132(33.0 \%)$ & $110(29.0 \%)$ & & \\
\hline & $\mathrm{AG}$ & $183(45.9 \%)$ & $202(53.0 \%)$ & & \\
\hline & GG & $85(21.2 \%)$ & $68(17.9 \%)$ & & 0.116 \\
\hline \multirow[t]{2}{*}{ Allele } & A & $447(55.9 \%)$ & $422(55.5 \%)$ & & \\
\hline & G & $353(44.1 \%)$ & $338(44.5 \%)$ & $1.014(0.83-1.239)$ & 0.89 \\
\hline rs 17285138 & HWE(P) & & & & 0.09 \\
\hline \multirow[t]{3}{*}{ Genotype } & AA & $126(31.6 \%)$ & $105(27.7 \%)$ & & \\
\hline & $\mathrm{AT}$ & $204(51.0 \%)$ & $204(53.6 \%)$ & & \\
\hline & $\mathrm{TT}$ & $70(17.4 \%)$ & $71(18.7 \%)$ & & 0.496 \\
\hline \multirow[t]{2}{*}{ Allele } & A & $456(57.0 \%)$ & $414(54.5 \%)$ & & \\
\hline & $\mathrm{T}$ & $344(43.0 \%)$ & $346(45.5 \%)$ & $1.108(0.907-1.353)$ & 0.315 \\
\hline
\end{tabular}

HWE(P), Hardy-Weinberg equilibrium P-value; OR, odds ratio; CI, confidence intervals. 

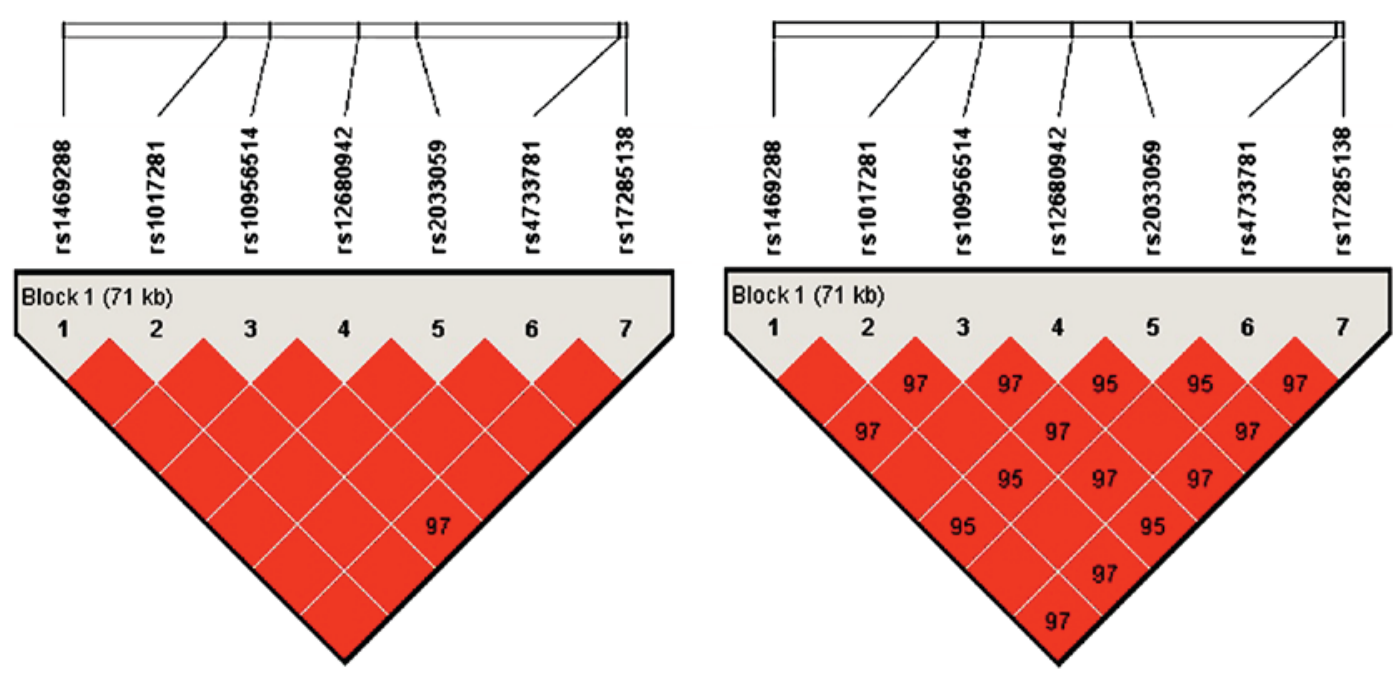

Figure 1. Linkage disequilibrium (LD) patterns of seven SNPs among CHB ( $n=103)$. The left displays Pairwise D' and the right displays r2. Strong linkage disequilibrium is represented by a high percentage. The red squares without a number indicate $100 \%$. The whole area was in strong linkage disequilibrium, can be used as a block.

$\mathrm{P}<0.05$ was considered to indicate a statistically significant difference.

\section{Results}

General characteristic of TB patients and healthy controls. The clinical characteristics of the total TB patients and healthy controls are summarized in Table III. TB patients were age matched with healthy controls. The age distribution between the patients $(55.4 \pm 12.4$ years) and controls $(55.7 \pm 12.1$ years) was not significantly different based on Mann-Whitney U test $(\mathrm{P}=0.675)$, as the data were non-normally distributed (Table I). Patients were also gender-matched with controls, no significant difference of gender was found between the two groups $\left(\chi^{2}=0.666, \mathrm{P}=0.415\right)$. Nationality of objects display no difference between patients and controls $\left(\chi^{2}=0.281, \mathrm{P}=0.869\right)$. Among 400 TB patients, 38 persons had family history of TB, while there were 29 persons with family history of TB in control group, no significance was found between two groups $\left(\chi^{2}=1.319, \mathrm{P}=0.251\right)$. A post hoc power analysis showed that Power value equals 0.8620 , meaning a high statistical effect (Fig. 1). The parameters used in power analysis were as follows: cases, 400; controls, 380; prevalence, 0.00178 ; odds ratio, 1.5070 ; minor allele frequency, 0.3536 .

Hardy-Weinberg equilibrium test. The rs10956514, rs1469288, rs2033059, rs4733781, rs1017281, rs17285138, rs12680942 SNPs were investigated in 400 pulmonary TB cases and 380 healthy controls in the Xinjiang Muslim population. rs10956514 site was not in Hardy-Weinberg equilibrium $(\mathrm{P}<0.05)$, so it was excluded from our research. The last six SNPs were in Hardy-Weinberg equilibrium in the control group and the pulmonary TB group $(\mathrm{P}>0.05)$ (Tables III and IV).

Genotype frequency distribution of ASAP1 gene SNPs in the Xinjiang Muslim population. We used the case-control analysis to examine whether 7 polymorphisms in the ASAP1 gene were associated with susceptibility to TB in Xinjiang

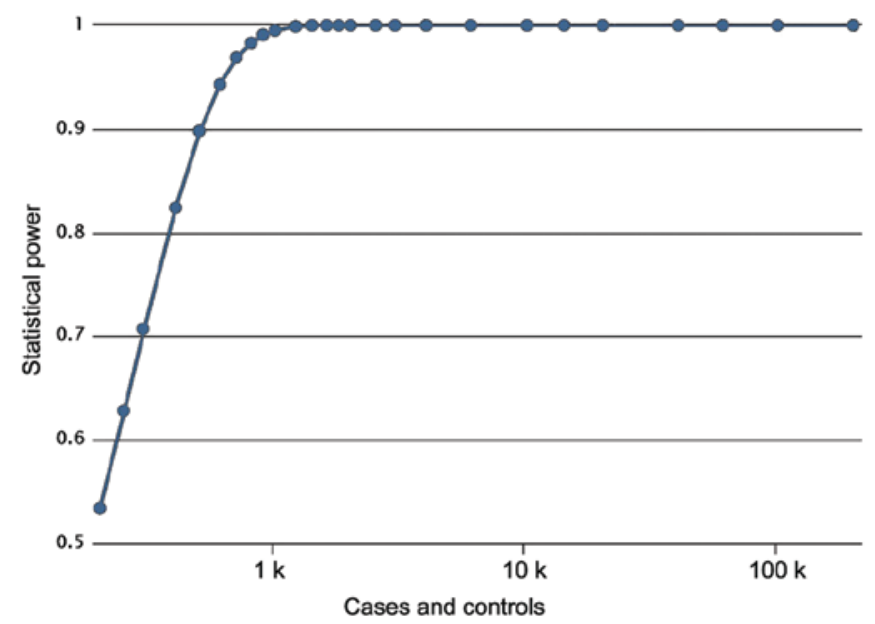

Figure 2. Linkage disequilibrium analysis.

Muslim population. The genotype and allelic frequencies of ASAP1 7 SNPs are summarized in Tables III and IV. Two polymorphisms were associated with $\mathrm{TB}(\mathrm{P}<0.05)$, while the other five SNPs showed no significance. For SNP rs4733781 the frequency of allele $\mathrm{A}$ in the pulmonary TB group was higher than that in the control group, and there was a significant difference between the two groups $(\mathrm{P}=0.046)$. While SNP rs1017281 was lower than that in the control group (Tables III and IV). The direction of effect for the associated alleles of rs4733781 and rs1017281 was the same as in Curtis et al (14).

Associations between genetic model of SNPs and TB risk. In order to find the optimal genetic model, we built codominant, dominant, recessive and overdominant model of ASAP1 gene polymorphisms. rs4733781 site was found related to the occurrence of TB in the recessive model $(\mathrm{CC}$ vs. $\mathrm{AA}+\mathrm{AC}$ : OR, 0.51; 95\% CI: 0.324-0.802; $\mathrm{P}=0.003$ ) and co-dominant model (AA vs. CC: OR, 1.926; 95\% CI: 1.198-3.097; $\mathrm{P}=0.006$ ). rs1017281 site was associated with $\mathrm{TB}$ in the recessive model (GG vs. AA+AG: OR, 1.792; 95\% CI: 1.135-2.828; $\mathrm{P}=0.011$ ) 
Table IV. Genotyping of rs10956514, rs4733781, rs1017281 in TB and control group in Xinjiang Muslin population.

\begin{tabular}{|c|c|c|c|c|c|}
\hline Site/genotype/allele & SNP & TB patients & Control & OR $(95 \% \mathrm{CI})$ & P-value \\
\hline rs10956514 & HWE(P) & & & & 0.013 \\
\hline \multirow[t]{3}{*}{ Genotype } & GG & $136(34.0 \%)$ & $133(35.0 \%)$ & & \\
\hline & GA & $207(51.8 \%)$ & $199(52.4 \%)$ & & \\
\hline & AA & $57(14.2 \%)$ & $48(12.6 \%)$ & & 0.799 \\
\hline \multirow[t]{2}{*}{ Allele } & G & $479(59.9 \%)$ & $465(61.2 \%)$ & & \\
\hline & A & $321(40.1 \%)$ & $295(38.8 \%)$ & $0.947(0.773-1.160)$ & 0.597 \\
\hline rs4733781 & HWE(P) & & & & 0.12 \\
\hline \multirow[t]{3}{*}{ Genotype } & AA & $194(48.6 \%)$ & $174(45.8 \%)$ & & \\
\hline & $\mathrm{AC}$ & $173(43.2 \%)$ & $149(39.2 \%)$ & & \\
\hline & $\mathrm{CC}$ & $33(8.2 \%)$ & $57(15 \%)$ & & 0.012 \\
\hline \multirow[t]{2}{*}{ Allele } & A & $561(70.1 \%)$ & $497(65.4 \%)$ & & \\
\hline & $\mathrm{C}$ & $239(29.9 \%)$ & $263(34.6 \%)$ & $1.242(1.004-1.537)$ & 0.046 \\
\hline rs1017281 & HWE(P) & & & & 0.56 \\
\hline \multirow[t]{3}{*}{ Genotype } & AA & $165(41.2 \%)$ & $171(45.0 \%)$ & & \\
\hline & $\mathrm{AG}$ & $187(46.8 \%)$ & $177(46.6 \%)$ & & \\
\hline & GG & $58(12.0 \%)$ & $32(8.4 \%)$ & & 0.034 \\
\hline \multirow[t]{2}{*}{ Allele } & A & $517(64.6 \%)$ & $519(67.3 \%)$ & & \\
\hline & G & $283(35.4 \%)$ & $241(31.7 \%)$ & $0.792(0.643-0.976)$ & 0.028 \\
\hline
\end{tabular}

HWE(P), Hardy-Weinberg equilibrium P-value; OR, odds ratio; CI, confidence intervals. Bold text, statistically significant.

Table V. Association of ASAP1 SNP genotypes with pulmonary TB under different genotype models.

\begin{tabular}{|c|c|c|c|c|c|c|}
\hline & Model & Genotype & Case & Control & OR $(95 \% \mathrm{CI})$ & P-value \\
\hline \multirow[t]{9}{*}{ rs4733781 } & & AA & $194(48.6 \%)$ & $174(45.8 \%)$ & 1 & \\
\hline & \multirow[t]{2}{*}{ Codominant } & $\mathrm{AC}$ & $173(43.2 \%)$ & $149(39.2 \%)$ & $0.96(0.712-1.296)$ & 0.791 \\
\hline & & $\mathrm{CC}$ & $33(8.2 \%)$ & $57(15 \%)$ & $1.926(1.198-3.097)$ & 0.006 \\
\hline & \multirow[t]{2}{*}{ Dominant } & AA & $194(48.5 \%)$ & $174(45.8 \%)$ & & \\
\hline & & $\mathrm{AC}+\mathrm{CC}$ & $206(51.5 \%)$ & $206(54.2 \%)$ & $1.115(0.841-1.477)$ & 0.448 \\
\hline & \multirow[t]{2}{*}{ Recessive } & $\mathrm{CC}$ & $33(8.2 \%)$ & $57(15.0 \%)$ & & \\
\hline & & $\mathrm{AC}+\mathrm{AA}$ & $367(91.8 \%)$ & $323(85.0 \%)$ & $0.51(0.324-0.802)$ & 0.003 \\
\hline & \multirow[t]{2}{*}{ Overdominant } & $\mathrm{AA}+\mathrm{CC}$ & $227(56.8 \%)$ & $231(60.8 \%)$ & & \\
\hline & & $\mathrm{AC}$ & $173(43.2 \%)$ & $149(39.2 \%)$ & $0.846(0.636-1.126)$ & 0.252 \\
\hline \multirow[t]{9}{*}{ rs1017281 } & & AA & $165(41.2 \%)$ & $171(45.0 \%)$ & 1 & \\
\hline & \multirow[t]{2}{*}{ Codominant } & $\mathrm{AG}$ & $187(46.8 \%)$ & $177(46.6 \%)$ & $0.913(0.679-1.229)$ & 0.549 \\
\hline & & GG & $58(12.0 \%)$ & $32(8.4 \%)$ & $0.532(0.329-0.862)$ & 0.01 \\
\hline & \multirow[t]{2}{*}{ Dominant } & AA & $165(41.2 \%)$ & $171(45.0 \%)$ & & \\
\hline & & $\mathrm{AG}+\mathrm{GG}$ & $235(58.8 \%)$ & $209(55.0 \%)$ & $0.858(0.646-1.140)$ & 0.29 \\
\hline & \multirow[t]{2}{*}{ Recessive } & GG & $48(12.0 \%)$ & $32(8.4 \%)$ & & \\
\hline & & $\mathrm{AA}+\mathrm{AG}$ & $352(88.0 \%)$ & $348(91.0 \%)$ & $1.792(1.135-2.828)$ & 0.011 \\
\hline & \multirow[t]{2}{*}{ Overdominant } & $\mathrm{AA}+\mathrm{GG}$ & $213(53.2 \%)$ & $203(53.4 \%)$ & & \\
\hline & & $\mathrm{AG}$ & $187(46.8 \%)$ & $177(46.6 \%)$ & $1.04(0.786-1.375)$ & 0.785 \\
\hline
\end{tabular}

Bold text, statistically significant.

and co-dominant model (AA vs. GG: OR, 0.532; 95\% CI: Linkage disequilibrium analysis. Haploview 4.2 was used to $0.329-0.826 ; \mathrm{P}=0.01$ ) (Tables $\mathrm{V}$ and VI). performed linkage disequilibrium analysis. As shown in Fig. 2, 
Table VI. The data of $\mathrm{D}^{\prime}$ and $\mathrm{r} 2$ among 7 SNPs of ASPAP1 gene in the Chinese Xinjiang Muslim population.

\begin{tabular}{llll}
\hline L1 & \multicolumn{1}{c}{ L2 } & $\mathrm{D}^{\prime}$ & $\mathrm{r}^{\wedge 2}$ \\
\hline $\mathrm{rs} 1469288$ & $\mathrm{rs} 1017281$ & 1 & 1 \\
$\mathrm{rs} 1469288$ & $\mathrm{rs} 10956514$ & 1 & 0.979 \\
$\mathrm{rs} 1469288$ & $\mathrm{rs} 12680942$ & 1 & 1 \\
$\mathrm{rs} 1469288$ & $\mathrm{rs} 2033059$ & 1 & 0.959 \\
$\mathrm{rs} 1469288$ & $\mathrm{rs} 4733781$ & 1 & 1 \\
$\mathrm{rs} 1469288$ & $\mathrm{rs} 17285138$ & 1 & 0.979 \\
$\mathrm{rs} 1017281$ & $\mathrm{rs} 10956514$ & 1 & 0.979 \\
$\mathrm{rs} 1017281$ & $\mathrm{rs} 12680942$ & 1 & 1 \\
$\mathrm{rs} 1017281$ & $\mathrm{rs} 2033059$ & 1 & 0.959 \\
$\mathrm{rs} 1017281$ & $\mathrm{rs} 4733781$ & 1 & 1 \\
$\mathrm{rs} 1017281$ & $\mathrm{rs} 17285138$ & 1 & 0.979 \\
$\mathrm{rs} 10956514$ & $\mathrm{rs} 12680942$ & 1 & 0.979 \\
$\mathrm{rs} 10956514$ & $\mathrm{rs} 2033059$ & 1 & 0.979 \\
$\mathrm{rs} 10956514$ & $\mathrm{rs} 4733781$ & 1 & 0.979 \\
$\mathrm{rs} 10956514$ & $\mathrm{rs} 17285138$ & 0.979 & 0.958 \\
$\mathrm{rs} 12680942$ & $\mathrm{rs} 2033059$ & 1 & 0.959 \\
$\mathrm{rs} 12680942$ & $\mathrm{rs} 4733781$ & 1 & 1 \\
$\mathrm{rs} 12680942$ & $\mathrm{rs} 17285138$ & 1 & 0.979 \\
$\mathrm{rs} 2033059$ & $\mathrm{rs} 4733781$ & 1 & 0.959 \\
$\mathrm{rs} 2033059$ & $\mathrm{rs} 17285138$ & 1 & 0.979 \\
$\mathrm{rs} 4733781$ & $\mathrm{rs} 17285138$ & 1 & 0.979 \\
\hline
\end{tabular}

linkage disequilibrium patterns for the cluster of 7 SNPs in the ASAP1 gene genotyped in a Chinese Xinjiang Muslim population. The results showed that the whole areas were strong linkage disequilibrium and they can be used as a block. Therefore, rs4733781 and rs1017281 were linked together, they should be considered as one locus.

\section{Discussion}

Xinjiang Uygur Autonomous Region bears heavier tuberculosis (TB) burden than other areas in China (3). The selection of candidate genes and detection of their polymorphism sites have been considered breakthroughs of TB prevention and treatment. Curtis et al (14) found single-nucleotide polymorphisms of ASAP1 gene was associated with the susceptibility to TB in the Russian population (14), while Hu et al (23) and Miao et al (24) found no associations. This may be partly due to differences between populations and small statistical power of the follow-up studies to detect weak genetic effects. However, no case-control analysis has been reported in Xinjiang Muslim population to date. Hence, investigating the susceptibility genes in Xinjiang Muslim population may provide access to control TB in Xinjiang Uygur autonomous region.

In the present study, we tested association of ASAP1 gene polymorphism and TB susceptibility in Xinjiang Muslim population by SNP genotyping. Our data suggested that ASAP1 rs4733781 and rs1017281 polymorphisms were associated with TB susceptibility in Xinjiang Muslim population
$(\mathrm{P}=0.046$ and $\mathrm{P}=0.028)$. While no significant associations were found in rs10956514, rs1469288, rs2033059, rs12680942 and rs17285138. In contrast to our findings, Hu et al (23) and Miao et al (24) found that ASAP1 gene polymorphism was not associated with TB susceptibility in Chinese population and Tibetan population. As known, there are ethnic variations of the allelic frequency distribution in the investigated polymorphism markers (25). In addition, numerous gene studies indicated that the risk variants of genetic heterogeneity and ethnicity specificity was associated with TB $(27,28)$. An explanation for these divergent results may involve whether polymorphism itself acts functionally and confers a truly altered susceptibility to TB disease or the associated allele was an unknown disease susceptibility allele in linkage disequilibrium. In this regard, it is necessary to note that excessive reduction of ASAP1 expression results in the impaired migration of Mycobacterium tuberculosis (MTB)-infected DCs, which may contribute to TB pathogenesis (14). Other co-variables may not be excluded, such as socio-economic factors, nutritional status, and interactions between genes (29). Therefore, in-depth study on the function of these sites is needed. In addition, in light of marginal P-values of associations between ASAP1 SNPs and TB susceptibility ( $\mathrm{P}=0.046$ and $\mathrm{P}=0.028$ ), multiple corrections should be considered in our later work, such as nationality, age, sex, smoking and family history. An independent Uyghur sample will be a good option to get converse results.

Regarding different genotype models, our results demonstrated that a trend of higher rs4733781 A allele and rs1017281 G allele in TB group compared to controls. Different genotype models revealed that subjects with rs4733781 A and rs1017281 G could be more susceptible to TB while subjects with rs4733781 $\mathrm{T}$ and rs1017281 A could be more resistant. The recessive model of rs4733781 (CC vs. AC+AA) in Xinjiang Muslim populations tended to be related with a lower TB risk $[\mathrm{P}=0.003, \mathrm{OR}=0.51(0.324-0.802)]$, while the recessive model of rs1017281 (GG vs. AA+AG) seemed to be related with a higher TB risk $[\mathrm{P}=0.011, \mathrm{OR}=1.792(1.135-2.828)]$. Additionally, the linkage disequilibrium analysis showed that rs4733781 and rs1017281 were linked together, they should be considered one locus. Next, profound studies will be performed to explore the potential functional roles of these two SNPs to help understand major findings. Do they participate in the immunoreaction caused by TB? What is the exact mechanism? Much work remains to be done.

In conclusion, ASAP1 rs4733781 and rs1017281 polymorphism may be a genetic factor for susceptibility to MTB among the Xinjiang Muslim populations. Further investigations of the functional role of SNP rs4733781 and rs1017281 and the genomic surrounding region are warranted.

\section{Acknowledgements}

Not applicable.

\section{Funding}

The study was supported by the National Natural Science Foundation of China (81673160) and The Xinjiang Uygur Autonomous Region Natural Science Foundation 
(2016D01B015) and The Xinjiang Uygur Autonomous Region Natural Science Foundation (2017D01A25).

\section{Availability of data and materials}

The datasets used and/or analyzed during the present study are available from the corresponding author on reasonable request.

\section{Authors' contributions}

XW contributed to the conception of the study; AM and XH contributed significantly to analysis and manuscript preparation; AL performed the data analyses and wrote the manuscript; FX helped perform the analysis with constructive discussions. All authors read and approved the final manuscript.

\section{Ethics approval and consent to participate}

The study protocol conformed to the ethical guidelines of the 1975 Declaration of Helsinki and was approved by the Ethics Committee of Department of Respiratory Medicine, Xinjiang Uygur Autonomous Region Chest Hospital. Each patient and control enrolled in this study provided a written informed consent.

\section{Consent for publication}

Not applicable.

\section{Competing interests}

The authors declare that they have no competing interests.

\section{References}

1. Zumla A, George A, Sharma V, Herbert RH, Oxley A and Oliver M; Baroness Masham of Ilton: The WHO 2014 global tuberculosis report - further to go. Lancet Glob Health 3: e10-e12, 2015.

2. National Technical Steering Group of the Epidemiological Sampling Survey for Tuberculosis; Implementing Office of the Epidemiological Sampling Survey for Tuberculosis: The prevalence of pulmonary tuberculosis in a national survey across China in 2010. Zhonghua Jie He He Hu Xi Za Zhi 35: 665-668, 2012 (In Chinese).

3. Li XX, Zhang H, Jiang SW, Liu XQ, Fang Q, Li J, Li X and Wang LX: Geographical distribution regarding the prevalence rates of pulmonary tuberculosis in China in 2010. Zhonghua Liu Xing Bing Xue Za Zhi 34: 980-984, 2013 (In Chinese).

4. Wubuli A, Xue F, Jiang D, Yao X, Upur H and Wushouer Q: Socio-demographic predictors and distribution of pulmonary tuberculosis (TB) in Xinjiang, China: A spatial analysis. PLoS One 10: e0144010, 2015.

5. Siroka A, Ponce NA and Lönnroth K: Association between spending on social protection and tuberculosis burden: A global analysis. Lancet Infect Dis 16: 473-479, 2016.

6. Png E, Alisjahbana B, Sahiratmadja E, Marzuki S, Nelwan R, Balabanova Y, Nikolayevskyy V, Drobniewski F, Nejentsev S, Adnan I, et al: A genome wide association study of pulmonary tuberculosis susceptibility in Indonesians. BMC Med Genet 13: $5,2012$.

7. Comstock GW: Tuberculosis in twins: A re-analysis of the Prophit survey. Am Rev Respir Dis 117: 621-624, 1978.

8. Varpela E: Studies on tuberculosis in twins. Duodecim 73: 242-250, 1957 (In Finnish).

9. Rubinstein U, Schachter J, Sharon N, Talnir R and Amir J: Tuberculosis in a pair of twins - the use of molecular biology methods for the detection of the source of infection. Harefuah 146 170-172, 248, 2007 (In Hebrew).
10. Khor CC, Vannberg FO, Chapman SJ, Guo H, Wong SH, Walley AJ, Vukcevic D, Rautanen A, Mills TC, Chang KC, et al: $\mathrm{CISH}$ and susceptibility to infectious diseases. N Engl J Med 362: 2092-2101, 2010.

11. Garzón MC, Angée DY, Llerena C, Orjuela DL and Victoria JE: Surveillance of Mycobacterium tuberculosis resistance to antituberculosis drugs. Biomedica 28: 319-326, 2008 (In Spanish).

12. Ladefoged K, Rendal T, Skifte T, Andersson M, Søborg B and Koch A: Risk factors for tuberculosis in Greenland: Case-control study. Int J Tuberc Lung Dis 15: 44-49, 2011.

13. Nie Z and Randazzo PA: Arf GAPs and membrane traffic. J Cell Sci 119: 1203-1211, 2006.

14. Curtis J, Luo Y, Zenner HL, Cuchet-Lourenço D, Wu C, Lo K, Maes M, Alisaac A, Stebbings E, Liu JZ, et al: Susceptibility to tuberculosis is associated with variants in the ASAP1 gene encoding a regulator of dendritic cell migration. Nat Genet 47: 523-527, 2015.

15. Tien DN, Kishihata M, Yoshikawa A, Hashimoto A, Sabe H, Nishi E, Kamei K, Arai H, Kita T, Kimura T, et al: AMAP1 as a negative-feedback regulator of nuclear factor- $\kappa \mathrm{B}$ under inflammatory conditions. Sci Rep 4: 5094, 2014.

16. Oda A, Wada I, Miura K, Okawa K, Kadoya T, Kato T, Nishihara H, Maeda M, Tanaka S, Nagashima K, et al: CrkL directs ASAP1 to peripheral focal adhesions. J Biol Chem 278: 6456-6460, 2003.

17. Nie Z, Hirsch DS, Luo R, Jian X, Stauffer S, Cremesti A, Andrade J, Lebowitz J, Marino M, Ahvazi B, et al: A BAR domain in the $\mathrm{N}$ terminus of the Arf GAP ASAP1 affects membrane structure and trafficking of epidermal growth factor receptor. Curr Biol 16: 130-139, 2006.

18. Hou T, Yang C, Tong C, Zhang H, Xiao J and Li J: Overexpression of ASAP1 is associated with poor prognosis in epithelial ovarian cancer. Int J Clin Exp Pathol 7: 280-287, 2013.

19. Lin D, Watahiki A, Bayani J, Zhang F, Liu L, Ling V, Sadar MD, English J, Fazli L, So A, et al: ASAP1, a gene at 8q24, is associated with prostate cancer metastasis. Cancer Res 68: 4352-4359, 2008.

20. Sabe H, Hashimoto S, Morishige M, Ogawa E, Hashimoto A, Nam JM, Miura K, Yano H and Onodera Y: The EGFR-GEP100Arf6-AMAP1 signaling pathway specific to breast cancer invasion and metastasis. Traffic 10: 982-993, 2009.

21. Onodera Y, Hashimoto S, Hashimoto A, Morishige M, Mazaki Y, Yamada A, Ogawa E, Adachi M, Sakurai T, Manabe T, et al: Expression of AMAP1, an ArfGAP, provides novel targets to inhibit breast cancer invasive activities. EMBO J 24: 963-973, 2005.

22. Bellamy R: Susceptibility to mycobacterial infections: The importance of host genetics. Genes Immun 4: 4-11, 2003.

23. Hu X, Peng W, Chen X, Zhao Z, Zhang J, Zhou J, Cai B, Chen J, Zhou Y, Lu X, et al: No significant effect of ASAP1 gene variants on the susceptibility to tuberculosis in Chinese population. Medicine (Baltimore) 95: e3703, 2016.

24. Miao R, Ge H, Xu L, Sun Z, Li C, Wang R, Ding S, Yang C and $\mathrm{Xu}$ F: Genetic variants at $18 \mathrm{q} 11.2$ and 8q24 identified by genomewide association studies were not associated with pulmonary tuberculosis risk in Chinese population. Infect Genet Evol 40: 214-218, 2016.

25. Yim JJ and Selvaraj P: Genetic susceptibility in tuberculosis. Respirology 15: 241-256, 2010.

26. Barrett JC, Fry B, Maller J and Daly MJ: Haploview: Analysis and visualization of LD and haplotype maps. Bioinformatics 21 : 263-265, 2005.

27. Delgado JC, Baena A, Thim S and Goldfeld AE: Ethnic-specific genetic associations with pulmonary tuberculosis. J Infect Dis 186: 1463-1468, 2002.

28. El Baghdadi J, Remus N, Benslimane A, El Annaz H, Chentoufi M, Abel L and Schurr E: Variants of the human NRAMP1 gene and susceptibility to tuberculosis in Morocco. Int $\mathrm{J}$ Tuberc Lung Dis 7: 599-602, 2003.

29. Perrin P: Human and tuberculosis co-evolution: An integrative view. Tuberculosis (Edinb) 95 (Suppl 1): S112-S116, 2015. International (CC BY-NC-ND 4.0) License. 